\title{
Maintaining Nursing Practice Standards While Changing With Times: SANC Perspective
}

\author{
Bethabile Lovely Dolamo* \\ Department of Health Studies, University of South Africa, South Africa \\ Received: May 16, 2018; Published: May 23, 2018 \\ *Corresponding author: BL Dolamo DCur, Department of Health Studies, University of South Africa, South Africa
}

\begin{abstract}
According to the South African Nursing Council (SANC), based on the Nursing Act, 33 of 2005, the practice of nursing/midwifery is grounded and embedded in articulated standards and ethical values and supported by a system of professional regulations (SANC sa). In 2004, the SANC published a Charter of Nursing Practice Draft 1 (chapter 4) on Standards for Nursing Practice [1]. This chapter is discussed in conjunction with the commitment of the profession of nursing [1]. Furthermore, the South African Nursing Council (2013) provided nurses with a code of ethics for nurses to render excellence in professionalism and advocacy for healthcare users. This code of ethics serves as a reminder to nursing practitioners of their responsibilities to protect, promote and restore health, to prevent illness, preserve life and alleviate suffering to their patients and clients. The code of ethics further serves as a declaration by nurses that they will always provide due care to the public and health care consumers to the best of their abilities while supporting each other in the process. This paper highlights the draft standards provided by the SANC and identify desirable behaviours, challenges and solutions for all the nurses registered under the SANC and working in public and private health institutions in South Africa.
\end{abstract}

Keywords: Nursing Practice Standards; Changing with the Times; South African Nursing Council; Maintaining Standards; Nursing and Midwifery; Nursing Practitioner

Abbreviations: SANC: South African Nursing Council; ANA: American Nursing Association; ICN: International Council of Nursing; SAQA: South African Qualifications Authority; CPD: Continuing Professional Development; HIV: Human Immuno-Deficiency Virus

\section{Introduction}

The standards of professional nursing practice are authoritative statements of the duties that all registered nurses, regardless of role, population, or speciality, are expected to perform competently [2]. As times change everything around demands change, and the behaviour of nurses around standards of professional practice are expected to change with the dynamics of the nursing profession. As the voice of all nurses, the role of the International Council of Nursing (ICN) is to ensure quality nursing care for all, maintain sound policies globally, ensure advancement of nursing knowledge, promote the presence worldwide of a respected nursing profession, and ensure a competent and satisfied nursing workforce. 'Be the change you want to see in the world' [3]. The question that arises is whether nursing practitioners in South Africa do take responsibility, act positively and create favourable working conditions as a priority. Child [4] found that "nursing in South Africa is in crisis".

According to the South African Nursing Council (SANC), based on the Nursing Act, 33 of 2005, the practice of nursing/midwife ry is grounded and embedded in articulated standards and ethical values and supported by a system of professional regulation (SANC sa). Therefore, preparation of nurse practitioners should encourage change while at the same time emphasizing maintaining practice standards. In 2002, a study to examine and evaluate nursing practice standards in a selected province in South Africa, experienced depressing moments throughout the research and revealing sheer negligence on the part of some nurse practitioners. The study concluded that the quality of professional conduct by nursing practitioners in clinical nursing care was inadequate in accordance with the standards and criteria set out for public hospitals [5]. The framework for practice of registered nurses in Canada addresses the person, health, environment and nursing as intertwined [6]. Under practice standards for regulated members, the College of Registered Nurses of Nova Scotia (CRNNS, 2017) further prescribes provision of knowledge-based practice, service to the public, and clinical practice, responsibility and accountability. The American Nursing Association practice standards tally with the nursing process steps [2]. 
In 2004, the SANC [1] published a Charter of Nursing Practice Draft 1 (chapter 4) on standards for nursing practice. This chapter (= chapter 4) reviewed the SANC's 1999 nursing/midwifery practice standards, which were also reviewed in the 2002 study in a selected province. This is discussed in conjunction with the commitment of the profession of nursing [1] and the generic competency framework for advanced nurse practitioners [7]. The South African Nursing Council [8] has further provided nurses with a code of ethics for nurses to render excellence in professionalism and advocacy for healthcare users. This code of ethics serves as a reminder to nursing practitioners of their responsibilities to protect, promote and restore health, to prevent illness, preserve life and alleviate suffering to their patients and clients. The code of ethics serves as a declaration by nurses that they will always provide due care to the public and health care consumers to the best of their abilities while supporting each other in the process.

This is a binding document with which the nursing practitioner and the profession have to comply. This code of ethics is the law that regulates the practice of nursing practitioners. This paper highlights the draft standards provided by the SANC [1] and challenges, and identifies desirable behaviour for all the nurses registered under the SANC and working in public and private health institutions in South Africa.

\section{The Role of The Sanc in Setting Nursing Practice Stand- ards}

Standards describe 'best practice' and ensure a consistent quality of performance. Practice standards are prerequisites for the promotion of safe, competent and ethical nursing practice (SANC sa: 2 ). The role of the SANC is to develop and maintain the practice standards for nursing practitioners. Among other things, the objects of the SANC are to establish, improve, control conditions, standards and quality of nursing education and training within the ambit of the Nursing Act (33 of 2005).

Therefore, the SANC is regarded as an education and training quality assurer in terms of section 5 of the South African Qualifications Authority Act (58 of 1995) for all nursing qualifications, and has a duty to protect the consumers of nursing services in general. To be a registered practitioner is the goal of almost every student enrolled in nursing education. It is a worthy goal reached through study, clinical practice and successful completion of the health professions qualification with the professional council, namely the SANC. Preparing students for the future as they enter the profession demands the need to look for opportunities to mentor them, take students to the real world and let them go beyond their comfort zone as students. The role of the professional organisation in setting standards for nursing is important. The main purpose of professional standards is to direct and maintain safe and clinically competent nursing practice. These standards are important to the profession because they promote and guide clinical practice. The South African nursing practitioner's practice is regulated by the SANC in terms of the scope of practice (SANC, 1984 as amended in 2004) and the Nursing Act (33 of 2005). The Nursing Act empowers the SANC to regulate nursing practice ethically, legally and professionally.
The International Council of Nursing (ICN), which is the international voice of nurses and midwives, linking with international organisations such as the World Health Organisation (WHO) and the World Bank (Muller and Petra, 2016), believes that the absence of legal controls for education and practice poses a serious risk of decline in standards of nursing care. Through policies and programmes aimed at building nurses' capacity to be knowledgeable and confident professionals, the ICN [9] helps people to take responsibility for and act positively to create conditions for local development. The problem only arises when developed countries actively recruit nurses and other healthcare professionals causing shortages in developing countries like South Africa. Up to 51 nurses in four years left the profession, and between 2016 and 2017, 20\% more people left the register in South Africa (2017). The nursing practitioner is to possess certain abilities in order to practise, including knowledge, skills and values.

The basic education and training of learner nurses in South Africa embraces a period of learning (knowledge), training (skills) and moulding (attitudes and behaviour). The SANC has put online a generic competency framework for advanced practitioners with five domains. Domain 1 requires professional, ethical and legal practice competency. Domain 2 requires care provision and management competency. Domain 3 requires competency on personal development and quality care. Domain 4 requires management and leadership competency and Domain 5 is on research. Figure 1 shows the SANC generic competency framework.

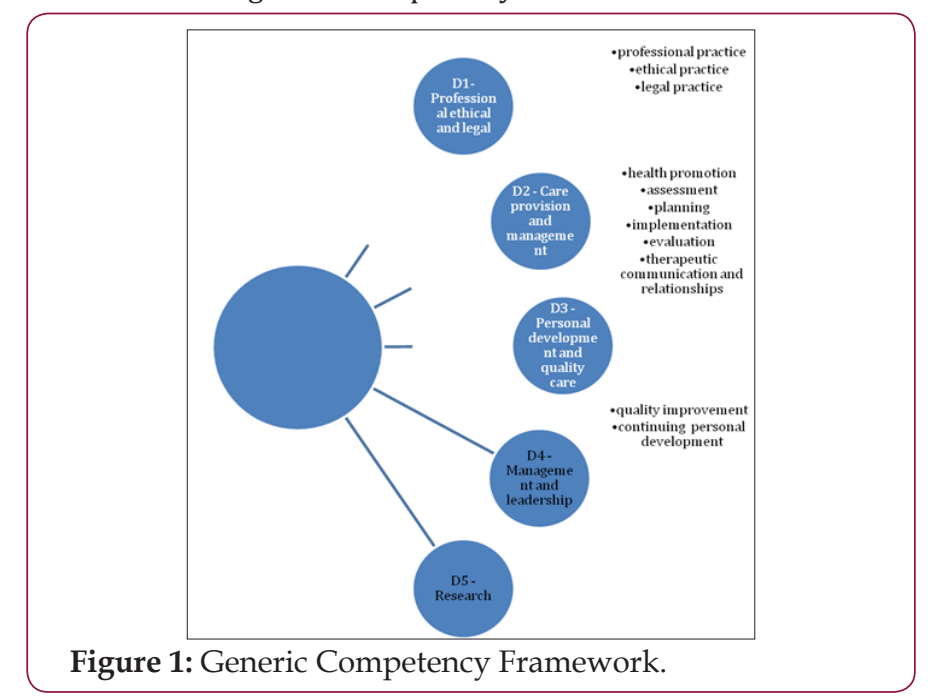

\section{Source: SANC (May 2014)}

The South African Qualifications Authority (SAQA) controls education in South Africa. Professional councils and Standard Generating Bodies (SGB) regulate the profession to ensure safe and quality practice [10] and remedial action strategies to ensure the continued professional behavioural competency of a nursing practitioner in providing quality patient care.

\section{Sanc Nursing/Midwifery Practice Standards}

The SANC has developed and reviewed the nursing/midwifery practice standards and the process does not appear to be complete since the scopes of practice have not been completed yet. The changes are necessary since there have been changes in the Nation- 
al Health Policy since 1994. The Draft Charter of Nursing Practice was published in 2004 with the aim of involving stakeholders for the development of scopes of practice, competency framework and standards of practice for nurses. The following practice standards taken from the draft charter of nursing practice are discussed. Figure 2 indicates the nurse/midwife practice standards.

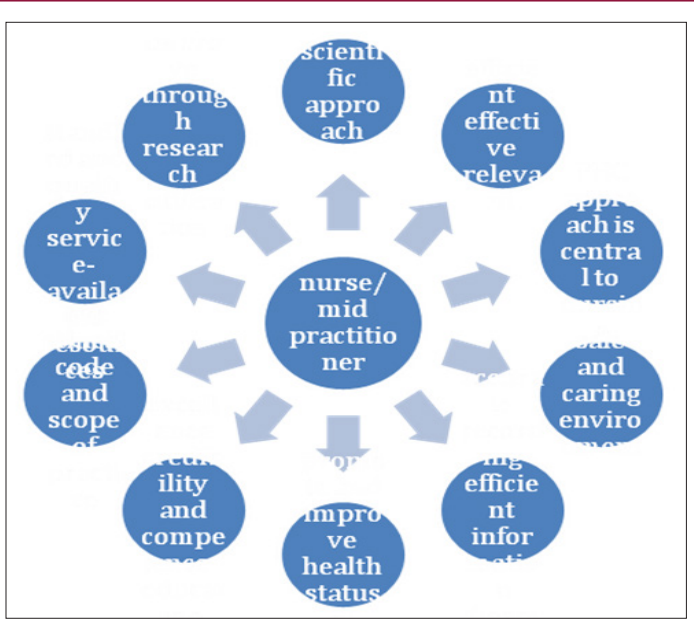

Figure 2: Nursing/Midwifery practice standards.

Source: Draft Charter of Nursing, 2004 (SANC 2004:29)

Scientific Approach Nursing: The education of a nurse in South Africa (under R425) is comprehensive, efficient and effective. The basic sciences are included to assist the nurse to be able to practise in the ambit of nursing the human being. Do not be fooled by those who think nursing is all about carrying bedpans. According to Polifroni [11] from Jones and Bartlett learning [sa], a philosophy of science is a perspective-a lens, a way one views the world, and in advanced practice the nurse acts from in every interaction with a patient, family, or a group, science as a way of knowing. The in-depth knowledge of the basic and contextual basic sciences is important not only to carry that bedpan, but also how to offer it to one's patients.

The following areas are included in nursing education and nursing practitioners need to have knowledge of all to be able to practice: Human biological sciences of anatomy and physiology; Chemical sciences; Pharmacology; Social sciences; Technology; Nursing science, legislation, education and management. The scientific approach in nursing agrees with the generic competency framework for advanced nursing practitioners [7] in Domain 2 on care provision and management. Under this domain, the advanced nurse practitioner through knowledge gained should be able provide health promotion, assessment of the care planning, and implement, evaluate and provide therapeutic communication and relationships at all levels of health care. This is in support of the scientific approach in nursing.

Nursing Practice is Efficient, Effective and Relevant to The Health Care Users' Needs: "Nursing is not a career for everyone. An effective nurse needs certain character traits to succeed. An effective nurse must be able to relate clinical data to the whole person, not just to a set of symptoms" (Perkins [sa]). During the four-year programme, nurses are prepared not only to offer safe care to patients/clients, but also to provide that care safely also to themselves. People injure their backs, get needle pricks and get infections. The four-year programme is planned in such a way that the advanced nursing practitioner is able to provide practice that is efficient, effective and relevant to the health care users' needs by practising responsibility and accountability. Domain 1 in the generic competency framework requires a nursing practitioner to be competent and practise professionally, ethically and legally (SANC, 2014). The guidance given at institutions of learning is planned for efficient and effective practice. The ICN [3] theme for nurses' day was based on this standard [3], 'Nurses: A force for change: care effective, cost effective'.

The Primary Health Care Approach is Central to all Nursing Practice: Canadian Nursing Association alluded to primary health care as a philosophy and approach that is integral to improving the health of all and the effectiveness of health service delivery in all care settings (CAN, [sa]). PHC focuses on the way services are delivered and puts people who receive those services at the centre of care. Appropriate health education to family and community, practice of health promotion, early detection and treatment of disease, and early referral in cases of complicated situations are outlined to learners and persons registered should promote, maintain and restore the health status of individuals, groups and community.

Promotion, Creation and Maintenance of a Safe and Caring Environment: Most learning and training from the first to the fourth year is on maintaining a safe and caring environment. The therapeutic environment focuses on physical, psychological and spiritual needs of the care users. The teaching on damp dusting, bed-making, spring cleaning, bed bath, mouth washes, hand washing, feeding the patient, talking and touching a patient and many other nursing procedures are very important. If nursing practitioners do not know these, how can and do they promote this environment? On completion and becoming registered as health providers, they should on a continuous basis hone and improve the skills and teach the neophyte nurses. The responsibility is on its own shoulders. The sitting-down syndrome of professional nurses should fall. Perkins [sa] takes this a step forward by giving the nurse the character of 'detailed-oriented', often spot signs of deterioration in a patient before the patient can verbalize it.

Accurate Recording, Efficient Management of Information and Teamwork: Accurate recording is part of a safe and caring environment. Patients have died of treatment over dosage, wrong medication, neglected care and many other medico-legal hazards that happen daily in patients' lives. Nurses complain daily that record-keeping consumes their time. Perkins [sa] alludes to this by saying that nurses must be great communicators. Communicating well does not always mean communicating a lot, it means communicating the relevant data concisely and accurately. Patient care given must be recorded as proof that it was given. In practice, the nurse practitioner works with a multidisciplinary team: doctors, psychologists, pharmacists, dieticians, physiologists, pastors and lately traditional doctors. As a professional nurse, there is a need to keep the multidisciplinary team relations open, transparent and honest. Bear in mind that a nurse is the patient's ADVOCATE. 
Nursing and Health Care is Managed to Promote and Improve Health Status of Health Care Users: Nursing and Midwifery Council [12] summarises the Code-Professional standards of practice and behaviour for nurses and midwives in the United Kingdom into four; that is, prioritise people, practice effectively, preserve safety and promote professionalism and trust. This is nursing and health care that is managed to promote and improve health status of health care users. The professional nursing practice must be accountable. The professional nurse should maintain confidentiality and patient privacy, and ensure continuity of patient care, harmonious integration of patient care by health professionals and health workers. S/he also has to decide whether s/he has the necessary knowledge, skills or experience to perform a specialized task.

Nursing Practitioners Maintain Excellence, Credibility and Competence Through Continued Education for Professional Growth and Development: Professional nurses are expected to keep abreast with developments in the profession. For the renewal of licence is to be based on continuing professional development (CPD). The certificate is no longer a permanent document to keep the professional on the job. The purpose of CPD is to promote and maintain professional standards of excellence, and ensure that the practice of nurses and midwives remains up to date and relevant to the constantly changing health needs of the South African community (SANC, 2017). The challenge is to grow, never stop reading, learning and self- development. Domain 3 encourages nursing practitioners on self-development for continuing personal growth [7].

Guided By the Legislative Framework and on Ethical Standards, Code of Conduct and Scope of Practice: The SANC provides rules and regulations that each nurse should have to guide his/ her practice. The professional file from the SANC (SANC Rules and Regulations) is not taken seriously by nursing practitioners. Legislation, including the Nursing Act, Health Act, and currently the Protection of Personal Information (POPI) Act, 4 of 2013, should guide the professional in practice. Domain 1 is a guide to this practice standard [7].

Maintain the Highest Standard and Quality of Health and Nursing Services With the Available Resources: All the standards are based on this standard. I call this standard the 'back to basics'. At the stage of qualifying, the nursing practitioner has been given all the skills to know what to do for a patient/client and where resources are not adequate. Always keep a record of what one did. Who knows, it might even come in handy when litigation is brought against the nursing practitioner or the employer. This standard proves whether one is a nurse or not. This is a professional, ethical and legal practice (SANC, 2014). This tally with the national core standards that were developed by the National Department of Health [13] to form the basic requirements for quality and safe care, while also reflecting on existing Government policies and guidelines in South Africa [14].

Improve Continuously through Research and Utilisation of Research Findings: Times have changed, computers and other technology gadgets are available to assist the practitioner to do re- search or to utilise research that has been done by others. Patients are becoming more informed and nursing practitioners feel as if patients are undermining them - they google and want to know more about their conditions. A doctor tells a patient 'you have Transverse Myelitis'; immediately the patient start googling using the smart phone and starts asking the nursing practitioner questions. Because some nursing practitioners are not up to date with research findings often become defensive in order to hide ignorance. Domain five (5) requires the nursing practitioner to do and utilise research findings in practice [7]. Research use can be facilitated through support and training; collaboration and partnership; dissemination strategies; networks; and strong, visible leadership. Research may not solve problems or make decisions, but can provide information for professional nurses to reduce risks in decision-making [15].

\section{Challenges}

The following are challenges that nursing practitioners face in post-apartheid South Africa. Inheriting disintegrated services, old buildings, poor financing and de-motivated health professionals resulted in: Shortage of resources, Human resources and equipment Human resources: the issue of staff shortages is a global problem but is more evident in developing countries. Developing countries like South Africa are losing health professionals to developed countries. South Africa has been losing nurses to developed countries, while at the same time nurses remaining in health institutions are expected to provide quality professional care according to nursing standards. In addition, rural health institutions are prone to lose staff to urban areas. ICN's international centre for human resources in nursing is dedicated to strengthening the nursing workforce globally through the development, on-going monitoring of comprehensive information, standards and tools on nursing human resources policy, management, research and practice [13].

Shortage of equipment: linen and medications are becoming a serious problem for nurses to function. It is difficult to manage staff because they become tired and irritable (burnout). The next thing they are booked off because they are sick. New conditions and diagnoses nursing practitioners were never prepared for: Ebola and human immuno-deficiency virus (HIV) are new conditions found in health institutions for which nursing practitioners were not prepared. Downgraded profession: This is the profession which one spent four years studying and is taken lightly by other health professionals, even political leaders. Remember, as you accompany other health professionals like doctors as nurses and midwives, you are a professional in your own right. Under-paid and overworked: Nurses study for four years. Those who do other health-related programmes at university, study anatomy and physiology with other health professionals and do the four-year degree find that when they complete, the others are paid more than the nursing practitioner. The nurses work more hours than the other health professionals. Why do people in high offices complain about shortage of nurses, or nurses leaving the country to other countries, when the nursing practitioners are not paid well? Those who soldier on sometimes cannot cope and develop medical conditions that are stress related. 
Poor working conditions: Poor working conditions include old buildings, no heating systems, long working hours, unfavourable leave cycles, lack of security at the institutions, dining halls changed to offices, no restrooms or recreational facilities. Electronic records are introduced in bits and pieces with little advancement in technology because of financial limitations in hospitals. Some hospitals in developing and rural areas do not have computers or advanced technology, while others have computers but are just white elephants missing this and that or there was no training.

\section{What to Do - Solutions}

a) Dr Brian Jolfe (CEO Bidvest Group) says, "If nurses do not deliver on nursing then the hospital is no longer a hospital. The world is changing and South Africa has changed a lot. Remember that frontline managers are the face of the hospital." Be leaders of the 21st century at places of work. "Perhaps as never before, leadership is urgently needed to envision the future, to reallocate resources, to monitor progress using information technology, and to engender both evidence-based, as well as outcomes-based health care for all" [16]. The leaders of the 21st century do not go where the path leads; they go where there is no path and leave a trail.

b) Updating standards without professional development, The SANC has an assignment and duty to visit institutions of clinical practice for inspection and staff development. When new information is published, circulars are sent to institutions but who sees that what has been prescribed is implemented? In 2016, the SANC started with road shows to the nine provinces. The focus seemed to be on membership renewal. Nursing practitioners, especially managers, need the SANC to support nurses and guide them on their practice [17-20].

c) The SANC should take its position on protecting the public by doing its job. Institutions are struggling to make ends meet. Professional development should make sure continuous development programmes are given to professional nurses, including practice standards.

\section{Conclusion}

Life is not about waiting for the storm to pass it is about learning to dance in the rain (Vivian Greene). The time has come when nursing practitioners should be involved, become members of professional organisations, and participate in political/professional debates. The SANC should develop programmes to upgrade nursing practitioners. Continuing professional development framework for nurses and midwives/accouchers in South Africa needs to be discussed and be put into practice by nurses themselves therefore, SANC should lead the way. Nursing practitioners should learn about policy development and be members in policy formulation. It is high time that nursing practitioners learn to love themselves, develop themselves, be proud of their profession, walk tall and give "best practice" to clients.

\section{Aknowledgement}

This paper was first presented in simpler format at the Limpopo College of Nursing graduations in July 2016. And was presented at a Forum for Academics conference in Barcelona Spain in June 2017.

\section{References}

1. (2004) South African Nursing Council (SANC) 2004, Draft Charter of Nursing Practice. Pretoria: SANC.

2. (2010) American Nursing Association (ANA) 2010, Nursing: Scope and Standards of Practice. Second edition. Draft basis for speciality nursing organizations. Silver Spring Maryland. American Nursing Association 2017. Practice Standards. Silver Spring Maryland, USA.

3. International Council of Nurses (ICN) (2017) Nurses the voice to lead in achieving Sustainable Development Goals.

4. Child K (2013) Nursing in South Africa is in crisis. Times live.

5. Dolamo BL (2002) the quality of professional conduct by nursing practitioners in selected public hospitals in Limpopo. Unpublished Doctoral thesis. Johannesburg: Rand Afrikaans University.

6. (2015) Canadian Nursing Association (CNA) 2015, Framework for the practice of Registered Nurses in Canada, USA.

7. (2014) South African Nursing Council (SANC) (2014) Generic competency framework for advanced practitioners. Pretoria: SANC.

8. (2013) South African Nursing Council (SANC) 2013, Code of ethics for nursing practitioners in South Africa. Pretoria: SANC.

9. (2015) International Council of Nurses (ICN) 2015 - Nurses: A force for change: Care effective, cost effective.

10. Dolamo BL, Peprah EO (2011) Contemporary issues in health services management. Cape Town Pearson.

11. Polifroni EC, Philosophy of Sciences: An introduction and Grounding for your practice. Samples.

12. (2015) Nursing and Midwifery Council (NMC) 2015, The Code Professional standards of practice and behaviour for nurses and midwives.

13. (2013) National Department of Health (NDOH) (2013) National strategic plan for nurse education, training and practice, 2012/13 - 2016/17. Pretoria: Government Printer.

14. Whittaker S, Shaw C, Spieker N, Limgar A (2011) Quality standards for healthcare establishments in South Africa.

15. Hemsley-Brown JV (2004) Facilitating research utilisation: a cross sector review of research evidence. International Journal of Public Sector Management 17(6): 534-553.

16. Slavkin HC (2010) Leadership for health care in the 21st century: A personal perspective. Journal of Healthcare Leadership (2): 35-41.

17. (2018) Canadian Nursing Association (CNA) 2018, Primary Health Care Position Statement.

18. (2009) International Council of Nurses (ICN), Delivering quality, serving communities: nurses leading care.

19. Perkins S, Characteristics of an effective nurse. work.chron.com/ characterstics-effective-nurse-9429.html.

20. (1995) Republic of South Africa (RSA) 1995, South African Qualifications Act, 58 of 1995. Pretoria: Government Printer. Republic of South Africa 2005. Nursing Act, 33 of 2005. Pretoria: Government Printer. 
(C) ( This work is licensed under Creative

Submission Link: https://biomedres.us/submit-manuscript.php

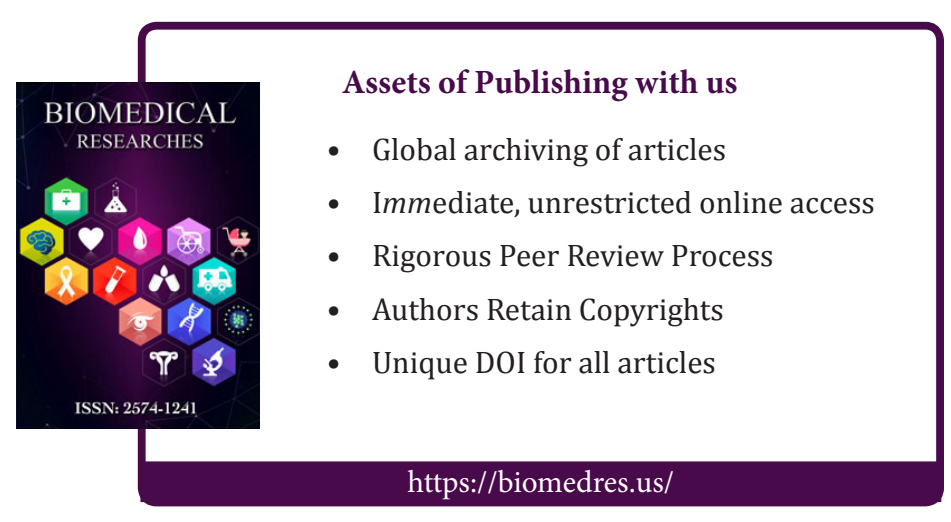

